Article

\title{
Selection Attributes of Innovative Digital Platform-Based Subscription Services: A Case of South Korea
}

\author{
Yoojin Kim and Boyoung Kim * \\ Seoul Business School, Seoul School of Integrated Sciences and Technologies (aSSIST), Seoul 03767, Korea; \\ egkim@ips.or.kr \\ * Correspondence: bykim2@assist.ac.kr
}

Received: 13 August 2020; Accepted: 24 August 2020; Published: 26 August 2020

\begin{abstract}
This study aimed to make an empirical analysis of the effects that the selection attributes of subscription services have on purchase intentions and continuous use intentions, based on the perceived value of digital platform-based subscription service users as a medium. A survey was conducted among 434 subscription service users in Korea, with content superiority, system quality, and service differentiation defined as key selection attributes based on a literature review. Upon analysis, content superiority and service differentiation were found to have a positive effect on perceived value, which in turn positively affected purchase intentions and continuous use intentions, which is why the hypothesis was consequently adopted. Service differentiation was also found to positively affect purchase intentions and continuous use intentions using perceived value as a medium. In contrast, system quality was found to have no effect on perceived value, nor did it affect purchase intentions or continuous use intentions using perceived value as a medium, which is why the hypothesis was rejected. In conclusion, among factors impacting decision-making or buying behavior among users of recent digital platform-based subscription services, new, unique, and meaningful content superiority was found to have a bigger impact compared to system-related aspects based on technology usability.
\end{abstract}

Keywords: selection attributes; subscription service; digital platform; content superiority; system quality; service differentiation

\section{Introduction}

Today's increase in mobile and online shopping and the spread of billing schemes such as monthly flat-rate plans have led to an expansion in the subscription services business [1]. A subscription service is a type of consumption where an individual purchases the right to use goods or services for a certain time period [2]. While the subscription service itself is an old existing service model, today's rapidly changing digital environment has led to the emergence of new business models that are linked to a variety of different types of subscription services [3]. Moreover, as customer management based on big data drives a continuous and direct shift in customer relationship management, many diverse digital business models have emerged reflecting this ongoing change. Subscription services themselves are also changing from the subscription model of the past, which was centered on product delivery, to a new type of service that leverages the digital environment-offering recommendations based on customer's historical purchase data, suggesting regular delivery intervals based on usage status, offering unlimited use of contents, etc. [4].

The McKinsey Report [5] projected that consumer goods subscriptions in the U.S. market would account for $15 \%$ of e-commerce shopping in 2016, and that globally, there would be around 28,000 companies providing subscription-type services as of 2017. Indeed, subscription-based 
businesses have been growing on a quantitative basis. The emergence of Netflix providing unlimited video streaming services in the 2000s shed new light on the subscription-based business model as the number of Netflix subscribers globally increased from 2.61 million in 2004 to more than 180 million as of the first quarter of 2020 [6]. The subscription business model started to draw attention in the retail space when Unilever acquired Dollar Shave Club, a subscription-based shaving kit delivery service provider for USD 1 billion in 2016 [7]. More and more categories of products such as cosmetics, dress shirts, razors, underwear, flowers, etc. have since been added on, as subscription services evolved into different types of subscription models: notably, predefined, curated and surprise [8].

Growth in subscription services is not limited to online contents. Subscription services are now defined as a new business model in their own right, rather than simply another approach to the sale of service products. Consequently, startups adopting a subscription-based business model have been on the rise across diverse industries. Manufacturers are also increasing their use of subscription service models to reinforce their digital platform services, while maintaining product competitiveness based on flat-rate market pricing [9].

Recently, as online shopping and smartphone usage becomes more universal, shopping behavior has been shifting away from buying to regular subscriptions driven by customized services that are based on intelligent digital platforms. Apple began to reinforce its lineup of subscription services including music, TV, Podcasts, etc., while Microsoft and Adobe converted their entire contents services into a subscription model, increasing their share of subscription sales significantly [10,11]. Advances in big data and AI technologies, in particular, have made it possible to offer recommendations to subscribers based on an analysis of their behavior when using certain goods and services, while also providing information-based services to consumers that reflect their needs as identified through data analysis, which has been a key driver behind the spread of subscription services versus simple purchases [12]. Consequently, the business-customer relationship is also shifting from a relationship simply based on the transaction itself into a relationship of ongoing mutual engagement, where trust and continuity are emphasized. As such, the study of consumption and purchasing behavior in subscription services represents an important issue for research purposes.

Previous research on subscription services mainly considered two aspects: first, consumer subscriptions were discussed from a financial and investment-related perspective because they were a source of stable income for companies [13,14]. Meanwhile, some researchers studied the value of subscription services from a marketing perspective, where the goal was to secure loyal customers with whom long-term relationships could be established $[15,16]$. However, in today's subscription service market, emphasis is now being placed on the creation of new business models and new markets, going beyond the earlier focus on sales policies directed at consumers. Not many studies exist to date, however, that look into consumer behaviors with respect to the new types of emergent subscription services that are based on digital contents and platforms.

This study aims to determine how the selection attributes of digital platform-based subscription services affect customers' purchase intentions and continuous use intentions through empirical analysis. In particular, an attempt was made to identify selection attributes affecting the perceived values of consumers in a transactional scenario of accessing subscription services-based on existing research on internet and mobile shopping, etc.- followed by an analysis of the ultimate effects these values have on consumers' purchase intentions and continuous use intentions. The results of this study are expected to have specific implications for companies in reinforcing their subscription services and developing strategies to establish their own subscription service business models. 


\section{Theoretical Background and Hypothesis Development}

\subsection{Subscription and Selection Attributes}

Selection is an act of choosing the most ideal solution of the issue among several alternatives which are intended to resolve an issue [17]. An attribute can be defined as a characteristic essential to a particular object or an inherent characteristic of a particular object [18]. In other words, a selection attribute is an attribute of a particular product or service that is directly relevant to a consumer's behavior-i.e., buying behavior, decision-making, repurchase intentions-which can ultimately have a positive impact on consumer behavior [19]. It has to do with how consumer attitudes are formed toward a particular attribute of a product or service that makes the difference between consumer preferences versus what they actually buy and also has to do with how certain attributes of a product or service are distinguishable from others. Bischof et al. [20] suggested that sales should be promoted by improving upon existing products while developing new products that fulfill consumer needs by taking into account the selection attributes of their respective target consumer groups.

Existing studies that looked at the selection intentions of subscription service users discussed individual customer characteristics [21,22], types of products delivered through subscription service [23], as well as service type-i.e., personalized, unlimited access, subscription box, etc. [8,24]. There was particular emphasis placed on the argument that the role of the intermediary was important for existing forms of regular subscription services-i.e., delivery of newspapers, magazines, dairy food products, etc.- depending on what type of direct transaction took place between the producer and consumer [25].

However, unlike regular subscription models of the past, the technological characteristics of contents and online now serve as important selection attributes in today's digital platform-based subscription services [26,27]. As a primary example, Rudolph et al. [28] classified product subscription models into pre-defined, curated, and surprise subscriptions according to the pre-notification status of consumers and contended that they were differentiated in terms of convenience, individually personalized services, and inspiration, respectively. Chung [22] noted that motivation for use had the strongest impact on consumer attitudes toward online shopping subscription services. Tao and Xu [29] suggested that factors such as knowledge, cognition, and acceptance by consumers served as selection attributes in their adoption intention toward fashion subscription retailing based on the innovation acceptance model.

In particular, Horng [30] suggested that system and service differentiation, the importance of contents, quality superiority, ease of use, and price quality were factors influencing consumers to pay for online contents subscription services. The relative advantages of subscription services as perceived by consumers in real life included saving time, convenience and ease of use, price quality, personalized services such as styling, elements of fun and surprise, expectations of a new style, etc., which are different selection attributes versus regular subscription services for general products. Consequently, this study chose content superiority, system quality, and service differentiation as the three key selection attributes for products or services delivered to consumers as a form of digital platform-based subscriptions services.

With digital platform-based subscription services, consumers often receive subscription box retail services (SBRS), which is an assortment of diverse contents or product categories that one can choose directly, rather than being a one-sided subscription to generally selected merchandise, which is why from this perspective, the superiority of new and diverse content should be taken into consideration for experiential consumption [23]. Accordingly, one of the important selection attributes of subscription services may be hedonic motivations such as the uniqueness, novelty, and surprise of the subscribed merchandise or contents, which can then convince users to subscribe $[15,22]$. As Morris and Powers [31] contended, features such as discriminative function and the quality (curated mechanism) of the subscription service contents can also serve as selection factors.

In addition, subscription services that are based on online and mobile digital platforms ultimately reflect the characteristics of new technology acceptance and factors such as usability, convenience, and 
utility may affect the selection attributes [32]. Chen and Fu [33] used the stimulus-organism-response (S-O-R) paradigm to suggest that whether or not the user feels that shopping takes less time or that the shopping process is convenient is an important factor and that the more innovative the consumers are, the more proactive they were in accepting subscription services. Lastly, the differentiating elements of the subscription service can also serve as important selection attributes [34]. Marion and Mimoun [24] indicated that providing curated information and goods was key to e-commerce subscription services. Digital platform-based subscription services can provide customized services to users based on big data analysis, and also offer product recommendations for online content subscriptions by analyzing consumers' usage data [35]. As users experience the convenience and usefulness of this kind of subscription mechanism as a differentiated service, they may recognize the distinct characteristics and value of subscription services, which are differentiated from other services, which may prompt selection by the consumer [36].

\subsection{Selection Attributes and Perceived Value}

Perceived value can be defined as the consumer's overall assessment of the utility of a product or service based on perceptions of what is received and what is given [37]. Sweeney and Soutar [38] defined perceived value as a multi-dimensional concept on which consumers' brand selection or purchase decisions are based, dividing them into emotional value, social value, performance/quality value, and price for money value. In previous studies on consumers' perceived value in online or mobile shopping, perceived value was defined as economic, social, and emotional values $[39,40]$. In particular, factors such as efficiency, excellence, play, aesthetics, status, esteem, ethics, and spiritual value were presented as the perceived value of subscription service users.

As already mentioned in many previous studies, perceived value is affected by leading variables such as product characteristics and selection attributes and may influence purchase intentions [41]. The perceived value of subscription service users is also affected by their service selection attributes $[13,23,30]$. How users perceive content superiority, system quality, or service differentiation and their satisfaction thereof may lead to their assessment of perceived value [42,43].

Hsu and Lin [44] made direct reference to their view that consumers' selection attributes and motivation for use may influence their perceived value of subscription services. Park et al. [45] explained that selection attributes such as product information, convenience, selectivity, delivery intervals, etc. may affect consumers' perceived value and perceived risk in subscription commerce. Based on this literature review, the hypothesis that the three selection attributes of content superiority, system quality, and service differentiation may affect consumers' perceived value toward subscription services was defined as follows.

Hypothesis 1 (H1). Among the selection attributes of subscription services, content superiority positively affects consumers' perceived value.

Hypothesis 2 (H2). Among the selection attributes of subscription services, system quality positively affects consumers' perceived value.

Hypothesis 3 (H3). Among the selection attributes of subscription services, service differentiation positively affects consumers' perceived value.

\subsection{Perceived Value, Purchase Intentions, and Continuous Use Intentions}

Intention is the will to engage in a future planned act to fulfill a personally set goal. It refers to the probability of a person's thoughts and attitude being put into action, while continuous use intention refers to a consumer's behavioral intent to consume a certain product or service again based on a memory (or experience) of past use [46]. Many studies have noted continuous use intention as the 
result of a satisfying experience, often referring to a positive act following customer satisfaction or a satisfying purchase experience [47].

Hoess et al. [48] defined purchase intention as an individual's tendency to purchase a particular product, or as their personal belief or willingness to form an attitude toward a certain object and express through a future act. They emphasized that the more positive a consumer's attitude or thoughts were toward a product or brand, the more likely they were to have purchase intentions and actually make a purchase. Such a positive effect may also lead to continuous use intentions [49]. Continuous use intention refers to a high likelihood for consumers to continue purchasing the product in the future. It is strongly characterized by a behavioral disposition toward direct consumption behavior and is highly correlated with actual repurchase behavior [50].

In particular, Calvo-Porral and Levy-Mangin [51] contended that purchase intentions in the online environment mostly occur in relation to service use and may later affect service experience satisfaction and continuous use intentions. Many different studies on consumption behavior within digital platforms have found perceived value to affect consumers' buying behavior and continuous use intentions $[44,52]$. Likewise for subscription services, purchase intention occurs when the value perceived by users is positive; actual purchase experience or purchase satisfaction resulting from the purchase intention may affect the individual's inclination to make recommendations or intentions to continue to use the subscription services or not [53].

Lee et al. [54] indicated that in mobile subscription commerce, consumers' economic, social, and emotional values may have a positive effect on their attitude and behavior royalty. Hamari et al. [55] noted that users' perceived value in subscribing to digital contents affected their use intentions. This study formulated the hypothesis that the value perceived by users of digital platform-based subscription services would positively affect their purchase intentions and continuous use intentions.

Hypothesis 4 (H4). Subscription service users' perceived value positively affects their purchase intentions.

Hypothesis 5 (H5). Subscription service users' perceived value positively affects their continuous use intentions.

Hypothesis 6 (H6). Subscription service users' purchase intentions positively affects their continuous use intentions.

\section{Research Methods}

\subsection{Research Model}

Based on the hypotheses drawn per literature review, a conceptual model was built, as shown in Figure 1. The selection attributes affecting subscription service use were 'content superiority' 'system quality', and 'service differentiation'. A research model was designed for pathway analysis to establish the causal relationship between each selection attribute and perceived value and to assess which attribute the center of gravity was concentrated on. The model was also designed to assess any impact on consumers' purchase intentions and continuous use intentions using perceived value as a medium and to identify any direct impact on continuous use intentions.

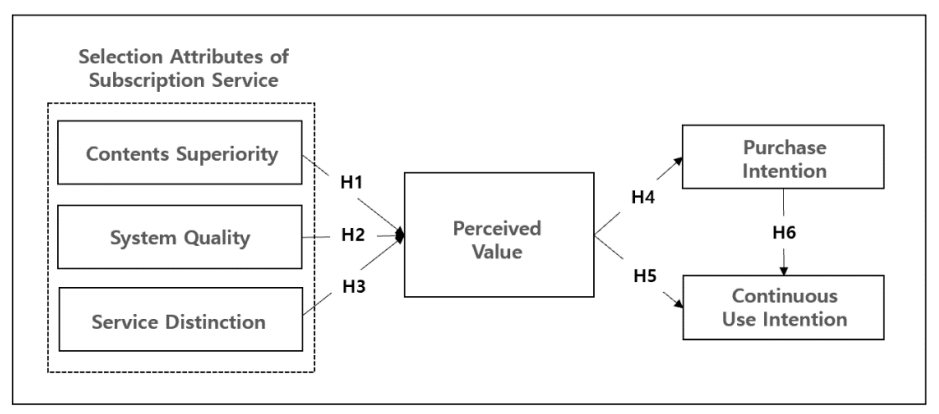

Figure 1. Research model. 


\subsection{Operational Definition and Measurement Variables}

For survey purposes, the operational definition and measurement items for each variable were designed on a 5-point Likert scale ( $1=$ totally disagree, $5=$ totally agree) based on the literature review (See Table 1). The selection attributes affecting the independent variable—subscription service-were defined as content superiority, system quality, and service differentiation based on the selection attributes of a subscription economy within a digital platform environment, as suggested by Tao and $\mathrm{Xu}$ [29] and Noorda [56]. Content superiority was comprised of four items (characteristics of offerings) - diversity, interest, up-to-date, and superiority compared to price; system quality comprised three items-stability, convenience, and information protection; while service differentiation comprised three items-uniqueness, responsiveness, and customization.

Table 1. Variable definitions.

\begin{tabular}{|c|c|c|c|}
\hline & tors & Survey Items & References \\
\hline \multirow{3}{*}{$\begin{array}{l}\text { Selection } \\
\text { Attributes }\end{array}$} & $\begin{array}{l}\text { Content } \\
\text { Superiority }\end{array}$ & $\begin{array}{l}\text { - Diverse assortment of goods } \\
\text { - Pleasant and interesting information } \\
\text { - Can access latest product information } \\
\text { - Good value for money offerings }\end{array}$ & \multirow{3}{*}{$\begin{array}{l}\text { Tao and } \mathrm{Xu}[29] \\
\text { Noorda [56] }\end{array}$} \\
\hline & $\begin{array}{l}\text { System } \\
\text { Quality }\end{array}$ & $\begin{array}{l}\text { - System is stable w/o disconnections or errors } \\
\text { - Easy and convenient to access and use } \\
\text { - No concerns about breach of personal data or leakage }\end{array}$ & \\
\hline & $\begin{array}{c}\text { Service } \\
\text { differentiation }\end{array}$ & $\begin{array}{l}\text { - Unique services } \\
\text { - Responsive to consumer needs or inquiries } \\
\text { - Good customized service }\end{array}$ & \\
\hline \multicolumn{2}{|c|}{ Perceived Value } & $\begin{array}{l}\text { - Subscription service has economic value } \\
\text { - Subscription service has social value } \\
\text { - Subscription service has emotional value } \\
\text { - Subscription service has informational value }\end{array}$ & Sun [57] \\
\hline \multicolumn{2}{|c|}{ Purchase Intentions } & $\begin{array}{l}\text { - Will use required subscription services no matter what } \\
\text { - Will use desired subscription service regardless of price }\end{array}$ & $\begin{array}{l}\text { Kang and Kim [58], } \\
\text { Hamari et al. [59] }\end{array}$ \\
\hline \multicolumn{2}{|c|}{ Continuous Use Intentions } & $\begin{array}{l}\text { - Will continue to use the current subscription service } \\
\text { - Willing to try out a new subscription service } \\
\text { - Willing to introduce the current subscription service to others }\end{array}$ & $\begin{array}{l}\text { Bhattacherjee [60], } \\
\text { Jeon et al. [61] }\end{array}$ \\
\hline
\end{tabular}

Perceived value as a parameter was comprised of four items-economic, social, emotional, and informational value - based on Sun [57]. The two dependent variables for subscription service purchase intentions were required use intentions and preferred use intentions, as suggested by Hamari et al. [58] and Kang and Kim [59]. Continuous use intentions were comprised of three items-continued use intentions, intention to use a new object, and use recommendations-based on prior studies by Bhattacherjee [60], Jeon et al. [61]. Upon measurement factor analysis, 'superiority compared to price' for content superiority and 'information protection' for system quality were not included; as a result, 17 out of 19 factors were ultimately used as final measurement factors, excluding the two mentioned above (see Table 1).

\subsection{Survey and Analytic Methods}

An online survey was conducted among consumers residing in South Korea who had used subscription services within the past year, via a research company panel etc., for 14 days from 4 February 2020 to 18 February 2020. A total of 442 questionnaires were returned and data from 434 copies were analyzed, with the exception of eight with insincere or missing answers. SPSS 26.0 (IBM, Seoul, Korea) was used for descriptive statistics and regularity analysis of demographic characteristics and variables; AMOS 26.0 (IBM, Seoul, Korea) was used for structural equation modeling to determine relations in diagram form through regression and pathway analysis. 
As shown Table 2, 54.6\% of the respondents were male, and $45.4 \%$ were female. Age was widely distributed from 20 s to 50 s: $13.8 \%$ for 20 s, $25.1 \%$ for 30 s, $31.8 \%$ for 40 s, and $28.3 \%$ for 50 s. Of the sample, $63.8 \%$ were university graduates. The usage status of subscription services included OTT services, books and contents, household or living goods, etc. TV and music streaming services were excluded since subscriptions and payments are mostly made online, and involve bundled service payment plans, which is a unique characteristic of the South Korean market. The respondents provided answers based on the brand they had been subscribed to for the longest; comparative analysis was carried out between two consumer groups in terms of purchase type: $67.3 \%$ unlimited access type, $32.7 \%$ regular delivery type.

Table 2. Demographic breakdown of survey participants.

\begin{tabular}{|c|c|c|c|}
\hline \multicolumn{2}{|c|}{ Division } & Frequency & Percent (\%) \\
\hline \multirow{3}{*}{ Gender } & Male & 237 & 54.6 \\
\hline & Female & 197 & 45.4 \\
\hline & Total & 434 & 100 \\
\hline \multirow{6}{*}{ Age (years) } & 20s (20-29) & 60 & 13.8 \\
\hline & 30s (30-39) & 109 & 25.1 \\
\hline & 40 s (40-49) & 138 & 31.8 \\
\hline & $50 s(50-59)$ & 123 & 28.3 \\
\hline & No answer & 4 & 0.9 \\
\hline & Total & 434 & 100 \\
\hline \multirow{5}{*}{ Education } & High School & 75 & 17.3 \\
\hline & University & 277 & 63.8 \\
\hline & $\begin{array}{c}\text { Graduate } \\
\text { school }\end{array}$ & 41 & 9.4 \\
\hline & No answer & 41 & 9.4 \\
\hline & Total & 434 & 100 \\
\hline \multirow{3}{*}{$\begin{array}{l}\text { Purchase } \\
\text { type }\end{array}$} & $\begin{array}{l}\text { Unlimited } \\
\text { access }\end{array}$ & 292 & 67.3 \\
\hline & $\begin{array}{l}\text { Regular } \\
\text { delivery }\end{array}$ & 142 & 32.7 \\
\hline & Total & 434 & 100 \\
\hline
\end{tabular}

\section{Results}

\subsection{Analysis Results of Reliability and Validity}

Composite reliability index analysis was carried out for the internal consistency of each item. Every item exceeded the reference of 0.7 , securing reliability with internal consistency for each factor. The convergent validity of items was determined based on factor loading, average variance extracted, and composite reliability [62]. A factor loading of 0.4 and Cronbach $\alpha \geq 0.6$, with statistical significance, can mean convergent validity [63]. In this study, the factor loading was 0.522 to 0.8672 with a t-value of at least 4.0 for all, which is statistically significant. Average extracted variance was 0.505 to 0.721 and Cronbach $\alpha$ was 0.750 to 0.904 , securing convergent validity. As for the goodness-of-fit index (GFI) of the model, $\chi^{2}(\mathrm{df})$ was 302.225 and $\chi^{2} /$ degree of freedom was 2.028 . With a GFI of 0.938 , the adjusted goodness-of-fit index (AGFI) of 0.913, a normal fit index (NFI) of 0.941, and a root mean square error of approximation (RMSEA) of 0.049 , the components of goodness-of-fit for the model were statistically significant on the basis of the reference presented by Hong et al. [64] (see Table 3).

The AVE (average variance extracted) and correlation coefficient between latent variables were estimated for discriminant validity. Generally, it can be said that when the square root of AVE from each latent variable is larger than the correlation coefficient with other concepts, the discriminant validity between latent variables is secured [65]. As presented in Table 4, the square root of AVE from 
each latent variable was larger than the correlation coefficient with other variables, and discriminant validity was secured for the tool.

Table 3. Results of reliability and convergent validity testing.

\begin{tabular}{|c|c|c|c|c|c|c|c|}
\hline Factors & Variable & $\begin{array}{l}\text { Standardized } \\
\text { Factor Loading }\end{array}$ & $\begin{array}{l}\text { Standard } \\
\text { Error }\end{array}$ & $t$-Value $(p)$ & CR & AVE & Cronbach $\alpha$ \\
\hline \multirow{3}{*}{$\begin{array}{c}\text { Content } \\
\text { Superiority }\end{array}$} & CS1 & 0.713 & & & \multirow{3}{*}{0.754} & \multirow{3}{*}{0.505} & \multirow{3}{*}{0.750} \\
\hline & CS2 & 0.725 & 0.078 & $13.289 * * *$ & & & \\
\hline & CS3 & 0.694 & 0.085 & $12.806^{* * *}$ & & & \\
\hline \multirow{2}{*}{$\begin{array}{l}\text { System } \\
\text { Quality }\end{array}$} & SQ1 & 0.737 & & & \multirow[b]{2}{*}{0.721} & \multirow[b]{2}{*}{0.564} & \multirow[b]{2}{*}{0.722} \\
\hline & SQ2 & 0.765 & 0.073 & $13.799 * * *$ & & & \\
\hline \multirow{3}{*}{$\begin{array}{c}\text { Service } \\
\text { Differentiation }\end{array}$} & SD1 & 0.622 & & & \multirow{3}{*}{0.777} & \multirow{3}{*}{0.540} & \multirow{3}{*}{0.778} \\
\hline & SD2 & 0.782 & 0.097 & $12.509^{* * *}$ & & & \\
\hline & SD3 & 0.788 & 0.1 & $12.564^{* * *}$ & & & \\
\hline \multirow{4}{*}{$\begin{array}{l}\text { Perceived } \\
\text { Value }\end{array}$} & PV1 & 0.84 & & & \multirow{4}{*}{0.905} & \multirow{4}{*}{0.703} & \multirow{4}{*}{0.904} \\
\hline & PV2 & 0.833 & 0.05 & $20.892 * * *$ & & & \\
\hline & PV3 & 0.854 & 0.052 & $21.705^{* * *}$ & & & \\
\hline & PV4 & 0.827 & 0.052 & $20.672 * * *$ & & & \\
\hline \multirow{2}{*}{$\begin{array}{l}\text { Purchase } \\
\text { Intentions }\end{array}$} & BI1 & 0.900 & & & \multirow[b]{2}{*}{0.837} & \multirow{2}{*}{0.721} & \multirow{2}{*}{0.834} \\
\hline & BI2 & 0.795 & 0.051 & $17.728^{* * *}$ & & & \\
\hline \multirow{3}{*}{$\begin{array}{l}\text { Continuous } \\
\text { Use Intentions }\end{array}$} & UI1 & 0.809 & & & \multirow{3}{*}{0.866} & \multirow{3}{*}{0.683} & \multirow{3}{*}{0.864} \\
\hline & UI2 & 0.867 & 0.052 & $19.856^{* * *}$ & & & \\
\hline & UI3 & 0.802 & 0.051 & $18.170^{* * *}$ & & & \\
\hline
\end{tabular}

Note: (1) Measurement model fit: $\chi^{2}$ (df) 302.225, $p=0$, DF 149, $\chi^{2} /$ DF 2.028, RMR 0.021, GFI 0.938, AGFI 0.913, NFI 0.941, TLI 0.96, CFI 0.969, RMSEA 0.049. (2) ${ }^{* * *} p<0.001$.

Table 4. Correlation matrix and Average Variance Extracted.

\begin{tabular}{cccccccc}
\hline Factors & AVE & CS & SQ & SD & PV & PI & CUI \\
\hline Content Superiority (CS) & 0.569 & 0.754 & & & & & \\
System Quality (SQ) & 0.564 & $0.618^{* *}$ & 0.751 & & & & \\
Service Differentiation (SD) & 0.540 & $0.574^{* *}$ & $0.572^{* *}$ & 0.735 & & & \\
Perceived Value (PV) & 0.703 & $0.517^{* *}$ & $0.527^{* *}$ & $0.583^{* *}$ & 0.839 & & \\
Purchase Intentions (PI) & 0.721 & $0.430^{* *}$ & $0.382^{* *}$ & $0.392^{* *}$ & $0.551^{* *}$ & 0.849 & \\
Continuous Use Intentions (CUI) & 0.683 & $0.457^{* *}$ & $0.396^{* *}$ & $0.453^{* *}$ & $0.604^{* *}$ & $0.668^{* *}$ & 0.827 \\
\hline Note: (1) The dark diagonal part is the square root value of average variance extracted. $(2)^{* *} p<0.01$.
\end{tabular}

\subsection{Analysis Results of Structural Model}

To determine the association between selection factors for subscription services via-a-vis perceived value, as well as behavioral and continuous use intentions, the goodness-of-fit of the structural model was determined, as presented in Table 5 . The absolute fit indexes of $\chi^{2}$ statistics, GFI, AGFI, and RMSEA and the incremental fit indexes, which are not affected by the sample but show the explanatory power of the model, such as NFI and the comparative fit index (CFI), were used. Generally, when GFI $\geq 0.9$, AGFI $\geq 0.8$, the root mean square residual (RMR), which refers to the variance size of the sample not explained by the model, $\leq 0.1$, and $\chi^{2}$ divided by the degree of freedom $\leq 5$, the goodness-of-fit of the model is satisfactory With the goodness-of-fit reference, $\chi^{2}(\mathrm{df})$ was $321.475(p=000), \chi^{2} /$ degree of freedom was 2.048, GFI was 0.935, and AGFI was $0.931(\geq 0.9)$. RMSEA was 0.049 , NFI was 0.937 , and CFI was 0.945 ; thus, it generally had good explanatory power.

Based on the final structural equation model pathway coefficient for hypothesis testing, the selection attributes affecting the perceived value of subscription services were found to be content superiority $(\beta=0.247, p<0.05)$ and service differentiation $(\beta=0.365, p<0.05)$; thus, Hypothesis 1 and 3 were adopted. In contrast, system quality failed to affect perceived value; thus, the hypothesis was rejected. 
As for the association between perceived value and subscription service purchase intentions and continuous use intentions in consumers, both purchase intentions $0.631(p<0.001)$ and continuous use intentions $0.308(p<0.001)$ were found to have a positive impact; thus, the hypotheses were adopted. Purchase intentions positively affected continuous use intentions, $0.598(p<0.001)$; thus, the hypothesis was adopted.

Table 5. Results of hypothesis testing.

\begin{tabular}{llcccc}
\hline Hypothesis & $\begin{array}{c}\text { Standardized } \\
\text { Factor Loading }\end{array}$ & $\begin{array}{c}t \text {-Value } \\
(\boldsymbol{p})\end{array}$ & $\begin{array}{c}\text { Status of } \\
\text { Acceptance }\end{array}$ & $\boldsymbol{R}^{2}$ \\
\hline H1 & Content Superiority $\rightarrow$ Perceived Value & 0.247 & $2.069^{*}$ & Accepted & \\
H2 & System Quality $\rightarrow$ Perceived Value & 0.159 & 1.293 & Rejected & 0.553 \\
H3 & Service Differentiation $\rightarrow$ Perceived Value & 0.365 & $3.182^{*}$ & Accepted & \\
\hline H4 & Perceived Value $\rightarrow$ Purchase Intentions & 0.631 & $12.644^{* * *}$ & Accepted & 0.398 \\
\hline H5 & Perceived Value $\rightarrow$ Continuous Use Intentions & 0.308 & $5.671^{* * *}$ & Accepted & 0.685 \\
H6 & Purchase Intentions $\rightarrow$ Continuous Use Intentions & 0.598 & $9.599^{* * *}$ & Accepted & 0.68 . \\
\hline
\end{tabular}

Note: (1) Structural model fit: $\chi^{2}$ (df) 321.475, p 0.00, DF 157, $\chi^{2} /$ degree of freedom 2.048, RMR 0.026, GFI 0.935, AGFI 0.913, NFI 0.937, TLI 0.959, CFI 0.945, RMSEA 0.049; (2)* $p<0.05$, *** $p<0.001$.

Bootstrapping was used for statistical analysis of the direct and indirect effects of the three factors-content superiority, system quality, and service differentiation-on purchase intentions and continuous use intentions through the medium of perceived value. Among the selection attributes, only service differentiation significantly affected purchase intentions $(0.230, p<0.05)$ and continuous use intentions $(0.250, p<0.05)$ based on perceived value as a medium. Perceived value significantly affected continuous use intentions through the medium of purchase intentions $(0.377, p<0.05)$. It was confirmed that service differentiation affects purchase intentions and continuous use intentions through perceived value as a medium. In contrast, content superiority $(0.461, p<0.001)$ and system quality $(0.396, p<0.001)$, neither of which was mediated by perceived value, directly affected purchase intentions and continuous use intentions. This result demonstrates that the selection attributes of digital platform-based subscription services can directly affect consumers' buying behavior without the mediation of perceived value (see Table 6).

Table 6. Direct, indirect and total effect.

\begin{tabular}{ccccc}
\hline Dependent Variable & Explanatory Variable & Direct Effect & Indirect Effect & Total Effect \\
\hline \multirow{4}{*}{ Purchase Intentions } & Perceived Value & $0.631^{* * *}$ & - & 0.631 \\
& Content Superiority & $0.422^{* * *}$ & 0.156 & 0.578 \\
& System Quality & $0.382^{* * *}$ & 0.100 & 0.482 \\
& Service differentiation & $0.392^{* * *}$ & $0.230^{*}$ & 0.622 \\
\hline \multirow{2}{*}{ Continuous Use } & Purchase Intention & $0.598^{* * *}$ & - & 0.598 \\
Intentions & Perceived Value & $0.308^{* * *}$ & $0.377^{*}$ & 0.685 \\
& Content Superiority & $0.461^{* * *}$ & 0.169 & 0.630 \\
& System Quality & $0.396^{* * *}$ & 0.109 & 0.505 \\
& Service Differentiation & $0.453^{* * *}$ & $0.250^{*}$ & 0.703 \\
\hline
\end{tabular}

\section{Conclusions}

This study provides an analysis of the key selection attributes and consumer behavior related to the purchase intentions and continuous use intentions of digital platform-based subscription service users. The main results are as follows: first, perceived value of subscription service users was positively affected by content superiority and service differentiation but was not affected by system quality. As found in the literature review, this result is consistent with findings that suggest that the quality attributes of products or services consumers experience exhibit a relatedness that 
allows users to perceive certain economic, social, emotional, and informational value. However, system quality was not perceived as a direct consumption value despite technological convenience or usefulness. While existing studies by Chuah et al. [66] and Jankowski et al. [67] indicated that system quality might positively affect consumers' perceived value in consuming digital contents or in using mobile applications, system quality was not found to be linked to consumers' perceived value in the context of choosing subscription services. Superiority of service contents was confirmed to have the strongest impact on perceptions of consumption value over technical superiority in the case of subscription services.

Second, while service differentiation affected purchase intentions or continuous use intentions through the medium of perceived value, content superiority or system quality was not mediated by perceived value but was found to directly affect purchase intentions and continuous use intentions. Ultimately, the selection attributes affecting digital platform-based subscription service users can directly affect consumer purchases and behavior without being mediated by perceived value. Previous studies generally indicated that only when consumers perceived motivations for use, selection attributes, and quality as the perceived value of service goods would there be purchase intentions or an influence on users' purchase satisfaction and repurchase [68-70]. Contrary to general service goods, however, this study confirmed that consumers' selection attributes can directly affect their buying behavior in the case of subscription services. Subscription service consumers tend to choose direct purchase intentions and continuous service use via selection attributes because they are inclined to choose contents through experiential consumption, while determining value at the time of service selection according to the customized service that is provided [71,72].

Third, the most important among factors directly affecting purchase intentions and continuous use intentions for subscription services was found to be content superiority. This result implies that subscription service goods may have content attributes such as content value, originality of service packages, freshness and uniqueness of contents, which may have a greater influence on customers compared to the traditional attributes of quality or price for general products and services. As previous studies $[73,74]$ contended, changes in the economic environment, including the shared economy and contents economy, have allowed today's customers to consume experiences and stories, emotions, and social values; therefore, subscription services must be understood as a transactional relationship where consumers' values and tastes affecting their consumption behaviors, instead of being viewed as a simple means of fulfilling people's needs by providing necessity products or services.

Today, the strategy of subscription services is understood as a business model creation strategy to create a new market through a diversity of platforms and ideas that go beyond simply selling new types of products. In addition, consumers understand subscription services as a market for buying new experiences and contents, not as just another convenient means of consuming products and services. While subscription service providers need to reinforce technical usability or system quality in terms of their online and mobile platforms, more importantly, they must place priority on creating a unique and creative method for offering services while also providing a diversity of new content. That is why this study offers a contribution to improve the new subscription service market by open innovation $[75,76]$.

This study has regional limitations as it was conducted among subscription service consumers in South Korea. Because the types and characteristics of subscription services vary by country and region-which can lead to different consumer behaviors-it is necessary to conduct empirical research in a global consumer groups with the objective of investigating the selection attributes for generalized subscription services and associated consumer behavior. This study had another limitation in that it includes no discussion on the major, general variables affecting consumers' buying behavior, such as tangibility and intangibility of goods, usage platforms, shopping time, lifestyle, etc., as control variables. Further research needs to give more consideration to diverse variables that can impact consumers' consumption behavior patterns associated with subscription services. Lastly, while this study was conducted based on a classification of subscription services into unlimited access vs. regular delivery types, subscription services may in fact have many different types, including random bundle 
deliveries, replenishment, curation packages, etc. Further research needs to investigate consumer behavior and purchase intentions, taking into account market characteristics by subscription service type, and make more specific and significant suggestions for subscription service providers.

Author Contributions: Funding acquisition, Y.K.; methodology, Y.K.; resources, Y.K.; supervision, B.K.; writing-original draft, B.K. and Y.K.; writing-review and editing, B.K. All authors have read and agreed to the published version of the manuscript.

Funding: This research received no external funding.

Acknowledgments: This research was supported by aSSIST (Seoul School of Integrated Sciences and Technologies).

Conflicts of Interest: The authors declare no conflict of interest.

\section{References}

1. IITP and MSTI. The Subscription Economy Era Has Arrive; Spread from Content to Various Consumer Goods. Available online: www.iitp.kr/kr/1/knowledge/policyDataViewB.it (accessed on 13 August 2020).

2. Carlos, A.; Gomez, U.; Neil, H. The Netflix recommender system: Algorithms, business value, and innovation. J. ACM Trans. Manag. Inf. Syst. 2016, 6, 13-14.

3. Tzuo, T.; Weisert, G. Subscribed: Why the Subscription Model Will Be Your Company's Future-And What to Do about It; Penguin Random House: London, UK, 2018.

4. Chen, Y.; Shang, Y.F. Factors influencing users' word-of-mouth intention regarding mobile apps: An empirical study. Int. J. Ind. Distrib. Bus. 2018, 9, 51-65. [CrossRef]

5. Chen, T.; Fenyo, K.; Yang, S.; Zhang, Z. Thinking inside the Subscription Box: New Research on E-Commerce Consumers. 2018. Available online: https://www.mckinsey.com/industries/technology-media-and-telecom munications/our-insights/thinking-inside-the-subscription-box-new-research-on-ecommerce-consumers\# (accessed on 13 August 2020).

6. Whitepaper: Subscription economy business perspective. Nets. 4 April 2018. Available online: https: //www.nets.eu/perspectives/Pages/Whitepaper-Subscription-economy-business-perspective.aspx (accessed on 13 August 2020).

7. Watson, A. Number of Netflix Paid Streaming Subscribers Worldwide 2011-2020. Available online: https://ww w.statista.com/statistics/250934/quarterly-number-of-netflix-streaming-subscribers-worldwide (accessed on 13 August 2020).

8. Mühlbach, S.; Arora, P. Behind the music: How labor changed for musicians through the subscription economy. First Monday 2020, 25. [CrossRef]

9. Lumpkin, G.T.; Dess, G.G. E-Business strategies and internet business models. Organ. Dyn. 2004, 33, 161-173. [CrossRef]

10. Xin, M. The impact of customer valuation uncertainty on software licensing. MIS Q. 2020, 44, 562-603. [CrossRef]

11. Lin, H.; Gursoy, D.; Zhang, M. Impact of customer-to-customer interactions on overall service experience: A social servicescape perspective. Int. J. Hosp. Manag. 2020, 87, 102376. [CrossRef]

12. Chitturi, R.; Raghunathan, R.; Mahajan, V. Delight by design: The role of hedonic versus utilitarian benefits. J. Market. 2008, 72, 48-63. [CrossRef]

13. Kim, M.K.; Park, M.C.; Lee, D.H.; Park, J.H. Determinants of subscriptions to communications service bundles and their effects on customer retention in Korea. Telecommun. Policy 2019, 43, 101792. [CrossRef]

14. Baxter, R.K. Subscription Business Models Are Great for Some Businesses and Terrible for Others. 2016. Available online: https://hbr.org/2016/07/subscription-business-models-are-great-for-some-businesses-and-t errible-for-others (accessed on 13 August 2020).

15. Woo, H.; Ramkumar, B. Who seeks a surprise box? Predictors of consumers' use of fashion and beauty subscription-based online services (SOS). J. Retail. Consum. Serv. 2018, 41, 121-130. [CrossRef]

16. Singh, D.P. Online shopping motivations, information search, and shopping intentions in an emerging economy. East Asian J. Bus. Manag. 2014, 4, 5-12.

17. Chuang, J.C.I.; Sirbu, M.A. Optimal bundling strategy for digital information goods: Network delivery of articles and subscription. Inf. Econom. Policy 1999, 11, 147-176. [CrossRef] 
18. Biehal, G.; Chakravarti, D. Consumers' use of memory and external information in choice: Macro and micro perspectives. J. Consum. Res. 1986, 12, 382-405. [CrossRef]

19. Lee, J.G.; Sadachar, A.; Manchiraju, S. What's in the box? Investigation of beauty subscription box retail services. Fam. Consum. Sci. Res. J. 2019, 48, 85-102. [CrossRef]

20. Bloemer, J.; Ko, J.; Du Ruyter, K. On the relationship between store image, store satisfaction and store loyalty. Eur. J. Market. 1998, 32, 499-513. [CrossRef]

21. Geisendorf, S.; Pietrulla, F. The circular economy and circular economic concepts: A literature analysis and redefinition. Co. Circ. Econ. 2018, 60, 771-782. [CrossRef]

22. Kan, H.; Kim, J.H. Factors influencing and use intention of social commerce: Focusing on the moderating effects of gender. J. Korean Oper. Res. Manag. Sci. Soc. 2013, 38, 117-139.

23. Bischof, S.F.; Boettger, T.M.; Rudolph, T. Curated subscription commerce: A theoretical conceptualization. J. Retail. Consum. Serv. 2020, 54, 101822. [CrossRef]

24. Marion, G.; Mimoun, M. My little box, oh my little box ... a video-netnographic study on the expression of values in subscription-based e-commerce. J. Appl. Bus. Res. 2015, 31, 1159-1166.

25. Doyle, P. Value-Based Marketing: Marketing Strategies for Corporate Growth and Shareholder Value; Wiley: Hoboken, NJ, USA, 2008.

26. Sinha, J.I.; Foscht, T.; Fung, T.T. How Analytics and AI Are Driving the Subscription E-Commerce Phenomenon. 2016. Available online: https://sloanreview.mit.edu/article/using-analytics-and-ai-subscription-e-commerce -has-personalized-marketing-all-boxed-up/ (accessed on 13 August 2020).

27. Ramkumar, B.; Woo, H. Modeling consumers' intention to use fashion and beauty subscription-based online services (SOS). Fash. Text. 2018, 5, 22-34. [CrossRef]

28. Rudolph, C.W.; Katz, I.M.; Lavigne, K.N.; Zacher, H. Job crafting: A meta-analysis of relationships with individual differences, job characteristics, and work outcomes. J. Vocat. Behav. 2017, 102, 112-130. [CrossRef]

29. Tao, Q.; Xu, Y. Fashion subscription retailing: An exploratory study of consumer perceptions. J. Fash. Mark. Manag. 2018, 22, 494-508. [CrossRef]

30. Horng, S.M. A study of the factors influencing users' decisions to pay for Web 2.0 subscription services. Total Qual. Manag. Bus. Excell. 2012, 23, 891-912. [CrossRef]

31. Morris, J.W.; Powers, D. Control, curation and musical experience in streaming music services. Creat. Ind. J. 2015, 8, 106-122. [CrossRef]

32. Lee, S.H. An exploration of initial purchase price dispersion and service-subscription duration. Sustainability 2019, 11, 2481. [CrossRef]

33. Chen, J.H.; Fu, J.R. On the effects of perceived value in the mobile moment. Electron. Commer. Res. Appl. 2018, 27, 118-128. [CrossRef]

34. Phang, D.C.W.; Wang, K.L.; Wang, Q.H.; Kauffman, R.J.; Naldi, M. How to derive causal insights for digital commerce in China? A research commentary on computational social sciences methods. Electron. Commer. Res. Appl. 2019, 35, 100837. [CrossRef]

35. Rosenbaum, S. Curation Nation: How to Win in a World Where Consumers Are Creators. 2011. Available online: https://www.amazon.com/Curation-Nation-World-Consumers-Creators/dp/0071760393 (accessed on 13 August 2020).

36. Hadi, N.U.; Aslam, N.; Gulzar, A. Sustainable service quality and customer loyalty: The role of customer satisfaction and switching costs in the Pakistan cellphone industry. Sustainability 2019, 11, 2408. [CrossRef]

37. Zeithaml, V. Consumer perceptions of price, quality and value: A means-end model and synthesis of evidence. J. Mark. 1988, 52, 2-22. [CrossRef]

38. Sweeney, J.; Soutar, G. Consumer perceived value: The development of a multiple item scale. J. Retail. 2001, 77, 203-220. [CrossRef]

39. Wu, L.Y.; Chen, K.Y.; Chen, P.Y.; Cheng, S.L. Perceived value, transaction cost, and repurchase-intention in online shopping: A relational exchange perspective. J. Bus. Res. 2014, 67, 2768-2776. [CrossRef]

40. Kim, Y.H.; Kim, D.J.; Wachter, K. A study of mobile user engagement (Moen): Engagement motivations, perceived value, satisfaction, and continued engagement intention. Decis. Support Syst. 2013, 56, 361-370. [CrossRef]

41. Karjaluoto, H.; Aijaz, A.S.; Hannu, S.; Saraniemi, S. How perceived value drives the use of mobile financial services apps. Int. J. Inf. Manag. 2019, 47, 252-261. [CrossRef] 
42. Yang, S.S.; Kim, I.H.; Jeong, C. Effects of digital music service acceptance factors on the perceived value and customer satisfaction. J. Korea Contents Assoc. 2016, 16, 456-463. [CrossRef]

43. Kuo, Y.F.; Wu, C.M.; Deng, W.J. The relationships among service quality, perceived value, customer satisfaction, and post-purchase intention in mobile value-added services. Comput. Hum. Behav. 2009, 25, 887-896. [CrossRef]

44. Hsu, C.L.; Lin, C.C.J. What drives purchase intention for paid mobile apps? - An expectation confirmation model with perceived value. Electron. Commer. Res. Appl. 2015, 14, 46-57. [CrossRef]

45. Park, H.B.; Lee, H.S.; Han, D.S. The effects of perceived service Attributes on continuance usage intention of Netflix. J. Cyber. Acad. Soc. 2020, 37. [CrossRef]

46. Oliver, R.L. Measurement and evaluation of satisfaction processes in retail setting. J. Retail. 1981, 57, $25-48$.

47. Labarbera, P.A.; Mazursky, D. A longitudinal assessment of consumer satisfaction/dissatisfaction: The dynamic aspect of the cognitive process. J. Mark. Res. 1983, 20, 337-349. [CrossRef]

48. Hoess, A.; Thormann, A.; Friedmann, A.; Heilmann, A. Self-supporting nanoporous alumina membranes as substrates for hepatic cell cultures. J. Biomed. Mater. Res. Part A 2012, 100, 2230-2238. [CrossRef]

49. Calvo-Porral, C.; Lévy-Mangin, J.P. Store brands' purchase intention: Examining the role of perceived quality. Eur. Res. Manag. Bus. Econ. 2017, 23, 90-95. [CrossRef]

50. Beneke, J.; Brito, A.; Garvey, K.A. Propensity to buy private label merchandise: The contributory effects of store image, price, risk, quality and value in the cognitive stream. Int. J. Retail Distrib. Manag. 2013, 43, 43-62. [CrossRef]

51. Calvo-Porral, C.; Levy-Mangin, J.P. Situational factors in alcoholic beverage consumption: Examining the influence of the place of consumption. Br. Food J. 2019, 121, 2086-2101. [CrossRef]

52. Son, H.Y.; Kang, M.S.; Ha, H.Y. Effects of perceived value and perceived risk on customer satisfaction and behavioral intention: A comparison between smartphone users and smartphone non-users. J. Mark. Manag. Res. 2012, 17, 69-92.

53. Spurgeon, E.; Linda, N.S. An exploratory study of consumer satisfaction and purchase behaviors for fashion subscription-based online services (SOS). JTSFT 2019, 76. [CrossRef]

54. Lee, K.W.; Choi, S.O.; Kim, J.H.; Jung, M.J. A study on the factors affecting decrease in the government corruption and mediating effects of the development of ICT and E-Government: A cross-country analysis. J. Open Innov. Technol. Mark. Complex. 2018, 4, 41. [CrossRef]

55. Hamari, J.; Hanner, N.; Koivisto, J. Why pay premium in freemium services? A study on perceived value, continued use and purchase intentions in free-to-play games. Int. J. Inf. Manag. 2020, 51, 102040. [CrossRef]

56. Noorda, R. The element of surprise: A study of children's book subscription boxes in the USA. Publ. Res. Q. 2019, 35, 223-235. [CrossRef]

57. Sun, Z.J. Effects of perceived value on consumer satisfaction and in-app purchase intention: Focused on the Chinese delivery app. E-Bus. Stud. 2018, 18, 317-330. [CrossRef]

58. Hassan, L.; Dias, A.; Hamari, J. How motivational feedback increases user's benefits and continued use: A study on gamification, quantified-self and social networking. Int. J. Inf. Manag. 2019, 46, 151-162. [CrossRef]

59. Zhou, R.; Liao, Y.; Shen, W.J.; Yang, S.L. Channel selection and fulfillment service contracts in the presence of asymmetric service information. Int. J. Prod. Econ. 2020, 22, 107504. [CrossRef]

60. Bhattacherjee, A. Understanding information systems continuance: An expectation-confirmation model. MIS Q. 2001, 25, 351-370. [CrossRef]

61. Jeon, H.M.; Kim, M.J.; Jeong, H.C. Influence of smart phone food delivery apps service quality on emotional response and app reuse intention-Focused on pad theory. Culin. Sci. Hosp. Res. 2016, 22, 206-221.

62. Chin, W.W. The Partial Least Squares Approach for Structural Equation Modeling. 1998. Available online: https://www.researchgate.net/publication/311766005_The_Partial_Least_Squares_Approach_to_Str uctural_Equation_Modeling (accessed on 13 August 2020).

63. Gefen, D.; Straub, D.; Boudreau, M.C. Structural equation modeling and regression: Guidelines for research practice. Commun. Assoc. Inf. Syst. 2000, 4. [CrossRef]

64. Hong, J.P.; Kim, B.Y.; Oh, S.H. The relationship benefits of auto maintenance and repair service: A case study of Korea. Behav. Sci. 2020, 10, 115. [CrossRef] [PubMed]

65. Fornell, C.; Larcker, D.F. Evaluating structural equation models with unobservable variables and measurement error. J. Mark. Res. 1981, 18, 39-50. [CrossRef] 
66. Chuah, H.; Wen, M.M.; Ramayah, T. The effect of perceived value on the loyalty of generation Y mobile internet subscribers: A proposed conceptual framework. Proced. Soc. Behav. Sci. 2014, 130, 532-541. [CrossRef]

67. Jankowski, J.; Hamari, J.; Watróbski, J. A gradual approach for maximising user conversion without compromising experience with high visual intensity website elements. Int. Res. 2019, 29, 194-217. [CrossRef]

68. Yang, Z.; Peterson, R.T. Customer perceived value, satisfaction, and loyalty: The role of switching costs. Psychol. Mark. 2004, 21, 799-822. [CrossRef]

69. Hsin, C.H.; Wang, H. The moderating effect of customer perceived value on online shopping behavior. Online Inf. Rev. 2011, 35, 333-359. [CrossRef]

70. Amjad, A.; Samen, A. Online service quality and brand equity: The mediational roles of perceived value and customer satisfaction. J. Int. Commer. 2015, 14, 509-530.

71. Yun, J.J.; Yang, J.H.; Park, K.B. Open innovation to business model: New perspective to connect between technology and market. Sci. Technol. Soc. 2016, 21. [CrossRef]

72. Radziwon, A.; Bogers, M. Open innovation in SMEs: Exploring inter-organizational relationships in an ecosystem. Technol. Forecast. Soc. Chang. 2019, 146, 573-587. [CrossRef]

73. Ahn, S.; Yang, S.J. Understanding consumer behavior on shared accommodation based on value-attitude-behavior hierarchy model: Focusing on Airbnb. J. Consum. Cult. 2018, 21, 97-119.

74. Tsou, H.T.; Chen, J.S.; Yunhsin, C.C.; Chen, T.W. Sharing economy service experience and its effects on behavioral intention. Sustainability 2019, 11, 5050. [CrossRef]

75. Yun, J.J.; Park, K.B.; Im, C.J.; Shin, C.H.; Zhao, X.F. Dynamics of social enterprises: Shift from social innovation to open innovation. Sci. Technol. Soc. 2017, 22. [CrossRef]

76. Yun, J.J.; Won, D.; Park, K.; Jeong, E.S.; Zhao, X. The role of a business model in market growth: The difference between the converted industry and the emerging industry. Technol. Forecast. Soc. Chang. 2019, 146, 534-562. [CrossRef]

(C) 2020 by the authors. Licensee MDPI, Basel, Switzerland. This article is an open access article distributed under the terms and conditions of the Creative Commons Attribution (CC BY) license (http://creativecommons.org/licenses/by/4.0/). 